ENNS, M. \& KARVELAS, L. (1995) Electrical dose titration for electroconvulsive therapy: a comparison of dose prediction methods. ConvulsiveTherapy, 11 86-93.

FARAH, A. \& MCCALL, W.V. (1993) Electroconvulsive therapy stimulus dosing: a survey of contemporary practices. ConvulsiveTherapy, $\mathbf{9}$, 90-94.

PETRIDES, G. \& FINK, M. (1996) The 'half-age' stimulation strategy for ECTdosing. ConvulsiveTherapy, 12 138-146.
PIPPARD, J. (1992) Audit of electroconvulsive therapy in two National Health Service regions British Journal of Psychiatry, 160 621-637.

ROYAL COLLEGE OF PSYCHIATRISTS (1995) The ECT Handbook. The Second Report of The Royal College of

Psychiatrists Special Committee on ECT. Council Report CR39. London: Royal College of Psychiatrists.

SACKEIM, H. A., PRUDIC, J.,

DEVANAND, D. P., et al (1993) Effects of stimulus intensity and electrode

placement on the efficacy and cognitive effects of electroconvulsive therapy. New England Journal of Medicine, $\mathbf{3 2 8}$ 839-848.

SWARTZ, C. M. \& ABRAMS, R. (1989) ECT Instruction Manual (3rd edn). Lake Bluff, IL: Somatics Inc

WEINER, R. D. (1997) Stimulus dosing with ECT: to titrate or not to titrate that is the question. Convulsive Therapy, 13,7-9.

original papers

*J. Laidlaw Consultant Psychiatrist, Brownhill Centre, Swindon Road, Chelten ham GL519EZ, P. Bentham Consultant Psychiatrist, G. Khan Senior Registrar, V. Staples Senior Registrar, A. Dhariwal Senior Registrar, B. Coope Senior Registrar, E. Day Senior House Officer, Queen Elizabeth Psychiatric Hospital, Birmingham, C. Fear Senior House Officer, Wotton Lawn, Gloucester, C. Marley Senior House Officer, J. Stemman Senior Registrar, Queen Elizabeth Psychiatric Hospital, Birmingham

Psychiatric Bulletin (2000), 24, 187-188

\title{
Special interest sessions in psychiatry
}

\section{Survey of one higher training scheme}

\section{AIMS AND METHOD}

While specialist registrars in psychiatry are entitled to spend one-fifth of their working week engaged in special interest sessions, little has been published on how the time is used. In order to describe what happens in practice, we conducted a semi-structured telephone survey of trainees on the

\author{
South-East Thames HigherTraining \\ Scheme in psychiatry. \\ RESULTS \\ The results indicate that while most \\ trainees $(78 \%)$ were satisfied with \\ their use of special interest time, \\ those using two sessions regularly \\ for a defined training purpose were \\ in the minority.
}

\begin{abstract}
CLINICAL IMPLICATIONS
Use of special interest sessions is generally good in the scheme surveyed. If uptake of sessions is to be improved, there needs to be even better local support as well as existing national recognition of the educational rights of trainees. The local support should be at the level of both trust and training scheme.
\end{abstract}

Career opportunities in psychiatry have evolved over time, with an increasing number of posts advertised as having a 'special responsibility' or 'special interest' in named sub-specialities. Appointment committees take guidance from the Royal College of Psychiatrists regarding the training and clinical experience that might be reasonably expected from candidates during their period of specialist training, but these are by no means fixed or mandatory. The Joint Committee on Higher Psychiatric Training (1995) provides some guidelines on the use of special interest time which may allow trainees to develop sufficient clinical experience in sub-specialities not offered in yearly core placements. Because special interest sessions often conflict with demands on trainees' time in busy clinical placements and because of the general level of uncertainty regarding the use of special interest time by juniors, we chose to conduct a survey of all specialist registrars and senior registrars on the SouthEast Thames regional scheme. Our aim was to find out how special interest time was being used and to provide a qualitative description of the opinions of trainees towards the value and difficulties in taking the sessions.

\section{The study}

All trainees in the old age and general adult South-East Thames Higher Training Scheme for psychiatry were invited to be interviewed over the telephone by one of the authors. The interview was semi-structured and used open and closed questions focused on the use, content and applicability of special interest sessions. Participants were given an opportunity to comment on how service demands had impacted on their training needs and asked to make suggestions for further improvements in the scheme.

A total of 34 trainees were invited to participate, of these two were on maternity leave at the time of the study, two were acting as locum consultants and three could not be contacted or did not wish to participate. At the time of the study M.S. and A.P. were specialist registrars on the scheme surveyed.

\section{Findings}

\section{Career aims}

A total of 27 doctors were surveyed of whom four (15\%) were old age trainees, and seven (26\%) hoped for dual accreditation with five in adult forensic psychiatry and two in adult psychiatry/psychiatry of learning disabilities.

\section{Use of special interest time}

Twenty (74\%) trainees were taking special interest sessions on a regular basis, of these nine (33.3\%) were 
taking two sessions per week, nine (33.3\%) one per week and one three sessions per month. Of those eight who were not using special interest time only three $(11 \%$ original papers

of total group) stated that they would have liked to use the time but felt unable to because of the service demands and pressures and difficulties in finding someone to cover for them. Two felt unsure how to use the time and three felt that they did not need a special interest (two were in old age psychiatry and the other had additional experience in two forensic posts).

Two of the 19 trainees taking special interest time felt that they had been forced to spend the time in an attachment of their consultant's choice rather than their own. Intotal $22 \%(6 / 27)$ of trainees felt unhappy with their current post, either because of the quantity or content of special interest sessions.

\section{How are special interest sessions used?}

The majority of trainees taking special interest time (13/19, $68 \%$ ) were using it in some form of psychotherapy attachment. Of these 13, only one was working towards a recognised formal training and three towards a psychotherapy diploma.

Three trainees used a total of five sessions in cognitive-behavioural psychotherapy; two used three sessions in cognitive-analytical psychotherapy; two used three sessions in family therapy; one used one session in dynamic psychotherapy; two used two sessions in group psychotherapy; four used six sessions in sex therapy; one used one session in neuropsychiatry; three used four sessions in forensic psychiatry; one used one session in liaison psychiatry; and one used one session in management.

\section{Discussion}

The minority who were unhappy felt that more pressure should be applied to the training consultants from the scheme organisers and suggested that timetables and job plans should be agreed with special interest time allocated prior to commencing a post.

A few trainees were unsure about how special interest time should be used and were unaware of the College guidelines on sub-speciality training. The more junior trainees asked for clearer information as to what attachments might be acceptable or possible whereas senior trainees (over two years of higher training) had been assertive in asking for what they wanted. Three trainees had received support for the funding of approved MSc or diploma training courses or gained approval to take the time to study or work in posts outside of the scheme.

Most trainees were pleased with the opportunity to develop special interest sessions and regarded it as a valuable way to broaden experience. The significance of the large number of trainees seeking psychotherapy experience was unclear. The more junior specialist registrars appeared less confident or assertive in taking special interest time.
The large majority of trainees were satisfied with the opportunities offered for special interest sessions, but the feedback suggested a need to improve the provision of more diverse special interest attachments.

Most trainees appreciated the flexibility that the scheme offered in supporting trainees who wished to use their time in novel ways (e.g. management course, attachments out of area). Not all participants appeared aware of the range of possibilities available and feared 'upsetting their trainers' by choosing to spend time off site from their core placements.

Many trainees had not seen the Joint Committee on Higher Psychiatric Training (1995) Handbook and relied on scheme organiser to inform and guide them in their clinical placement reviews.

\section{Limitations to the study}

Telephone interviews were chosen as they were expected to yield a better response rate than questionnaires; this may have caused some trainees to be inhibited in giving negative feedback since their identities were known. Both interviewers were personally known to many of the trainees and are strongly committed to the idea of special interest opportunities and this also may have influenced respondents' replies.

The results cannot be generalised to other schemes and a nation-wide survey from the College scheme visits would be of interest, as would a survey of the trainers' attitudes towards the use of special interest sessions.

\section{Recommendations}

(a) Special interest sessions are considered to be valuable by the majority of higher psychiatric trainees.

(b) Scheme organisers need to provide more explicit guidelines to trainees and trainers on how and where special interest sessions can be used.

(c) Job descriptions should allow for special interest time with appropriate cover arrangements.

(d) Up-to-date lists of possible placements and consultant trainers with particular special interests should be circulated to trainees.

(e) Further work is needed to evaluate the training value of special interest time and to explore how these sessions should be monitored, supervised and funded.

(f) There is a need for the College to regularly publish clear guidelines regarding sub-speciality training.

\section{Reference}

JOINT COMMITTEE ON HIGHER PSYCHIATRIC TRAINING (1995) Handbook (7th edn) Occasional Paper OP 27, pp. 9 \& 28. London: Royal College of Psychiatrists.

*Matthew Stephenson Consultant Psychiatrist in Learning Disabilities, Leeds Community and Mental Health ServicesTeaching NHS Trust, The Lodge, Crooked Acres, 1 Spen Lane, Leeds LS5 3EJ， Alison Puffett Consultant Psychiatrist in General Adult Psychiatry, Kingswood Mental Health Centre, 180-186 Union Street, Maidstone, Kent ME14 1EY 